\title{
Computação (Des)plugada: um relato de experiência sobre o ensino remoto de Números Binários em tempos de distanciamento social
}

\author{
Sabrina B. Sassi ${ }^{1}$, Cristiano Maciel $^{12}$, Vinícius Carvalho Pereira ${ }^{3}$ \\ ${ }^{1}$ Programa de Pós-graduação em Educação - Universidade Federal de Mato Grosso \\ (UFMT) - Cuiabá - MT - Brasil \\ ${ }^{2}$ Instituto de Computação - Universidade Federal de Mato Grosso (UFMT) - Cuiabá - \\ MT - Brasil \\ ${ }^{3}$ Instituto de Linguagens - Universidade Federal de Mato Grosso (UFMT) - Cuiabá - \\ MT - Brasil \\ sabrinabsassi@gmail.com, cmaciel@ufmt.br, viniciuscarpe@gmail.com
}

\begin{abstract}
This paper presents an experience report on remotely teaching the concept of Binary Numbers to students from a full time School in Mato Grosso, in Applied Mathematics Studies classes. Our goal is to describe the Mathematics teacher's perception of using unplugged activities in her remote classes and how those can relate to Mathematics. The activities were extracted from the book Computer Science Unplugged; the methodology adopted was Unplugged Computing. The findings are systematized into perceptions and recommendations concerning the pandemic moment we live in, and the challenges imposed by remote teaching.
\end{abstract}

Resumo. Este artigo apresenta um relato de experiência de ensino do conceito de Números Binários para alunos de uma escola Plena de Mato Grosso, realizada na aula da disciplina Estudo Aplicado de Matemática. O objetivo deste é descrever a percepção da professora de Matemática quanto ao uso de atividades desplugadas em suas aulas remotas e a aproximação desses conceitos com a Matemática. Foram realizadas atividades disponibilizadas pelo livro Computer Science Unplugged, tendo como metodologia a Computação Desplugada. Os achados são sistematizados em percepções e recomendações que estão permeadas com questões afetas ao momento pandêmico que vivemos, de ensino remoto e seus desafios.

\section{Introdução}

As escolas brasileiras são hoje orientadas pelo instrumento de gestão pedagógica e de organização curricular intitulado Base Nacional Comum Curricular (BNCC), o qual define os conhecimentos essenciais, dentro dos componentes curriculares, aos quais os estudantes têm direito de acesso e apropriação durante toda sua trajetória na Educação Básica. Dentre as diversas propostas previstas na BNCC, o Pensamento Computacional (PC) e conceitos correlatos à área de computação, como Cultura Digital, Tecnologias Digitais da Informação e da Comunicação (TDIC), Redes Sociais, Algoritmos etc., são referenciados explicitamente [Brasil, 2021]. 
Em leitura detalhada da BNCC, o tema PC é referenciado principalmente na Área de Matemática do Ensino Fundamental, quando se refere a processos matemáticos, nas unidades temáticas Álgebra, Números, Geometria e Probabilidade e Estatística; e ao tratar de modo mais geral sobre as aulas de Matemática. A BNCC evidencia que "a área de Matemática, no Ensino Fundamental, centra-se na compreensão de conceitos e procedimentos em seus diferentes campos e no desenvolvimento do pensamento computacional, visando à resolução e formulação de problemas em contextos diversos" [Brasil, grifo nosso,2021, p. 471]. Ainda segundo esse documento, o Ensino Médio amplia e aprofunda as aprendizagens construídas nas etapas anteriores. Na prática, há vários estudos sobre a integração do $\mathrm{PC}$ na Educação Básica, sendo uma das propostas a abordagem da Computação Desplugada (CD), que consiste na possibilidade de trabalhar o pensamento computacional, bem como conceitos e habilidades computacionais dentro do currículo escolar, com base nos objetivos de aprendizado, sem o uso das tecnologias.

Em março de 2020 foi decretado pela Organização Mundial da Saúde (OMS) o estado de pandemia da Covid-19. Como combate à sua disseminação rápida, diversas medidas foram orientadas por órgãos nacionais e internacionais, com destaque para a necessidade de isolamento social [WHO 2020]. Desse modo, as aulas presenciais de escolas brasileiras, públicas e privadas foram suspensas e todo o planejamento pedagógico precisou ser revisado. O impacto sofrido pelas Escolas Plenas devido ao isolamento social é considerável quanto o fazer pedagógico nas concepções dos princípios e metodologias do projeto escola, bem como na prática pedagógica e nas estratégias para operar o currículo em tempo integral.

Diante de todo o impacto causado pela necessidade urgente de distanciamento social, foi necessário que cada rede ou instituição escolar buscasse, dentro de sua realidade, uma solução para garantir a continuidade dos estudos, acolher e ajudar todos os alunos do estado e lidar da melhor forma possível com a situação vivenciada. A utilização de aulas remotas ou atividades assíncronas foi admitida como uma das alternativas pedagógicas firmado pelo ato normativo Decreto 510 de 03 de junho de 2020 [Mato Grosso, 2020] que manteve a suspensão das aulas presenciais e determinou para a Secretaria de Estado de Educação a elaboração de um Plano Estratégico com diretrizes para o retorno às aulas em conformidade com a Resolução Normativa 03 de 10 de junho do Conselho Estadual de Educação, tomando como base as informações levantadas por meio de um questionário online elaborado pela Seduc-MT e aplicado pelas escolas estaduais, aos pais/responsáveis dos estudantes, no segundo semestre de 2020 e no início do ano letivo de 2021, diante da disponibilidade ou não, de recursos para acesso às aulas.

Em uma recente pesquisa sobre Revisão Sistemática no campo do uso da CD na Educação Básica e Superior [Sassi; Maciel; Pereira, 2021], os autores identificaram somente uma pesquisa [Figueiredo et al, 2020] publicada no Workshop de Informática na Escola (WIE) que faz uso da CD no ensino remoto. Nessa esteira, a pesquisa em tela questiona: há possibilidade de trabalhar Computação desplugada nas aulas remotas como uma alternativa para o ensino de conceitos computacionais em paralelo com conceitos matemáticos na Educação Básica? Sustentado pelas referências da BNCC para a área de Matemática quanto ao desenvolvimento do Pensamento Computacional (PC), este estudo contempla um estudo exploratório com abordagem qualitativa e tem como objetivo analisar a percepção de uma professora de Matemática quanto ao uso de atividades desplugadas na disciplina de Atividades Aplicadas em Matemática para o 
ensino de conceitos fundamentais da Ciência da Computação e da Matemática, no contexto de ensino remoto imposto pela pandemia.

O trabalho está estruturado da seguinte forma: na seção 2 é apresentado a estrutura pedagógica da Escola Plena de Mato Grosso; na seção 3 é descrita a experiência na aula remota; na seção 4 são apresentados os resultados e discussões, por fim, na última seção, são apresentadas as considerações finais.

\section{Estudo Aplicado de Matemática na Escola Plena de Mato grosso}

O modelo da escola em tempo integral no estado de Mato Grosso foi implementado no ano de 2017, disposto na Portaria de número 035/2016/GS/SEDUC/MT, com denominação de Escola Plena, inicialmente atendendo o Ensino Médio e, no ano de 2018, ampliando-se para o Ensino Fundamental, do $6^{\circ}$ ao $9^{\circ}$ ano. O Projeto Pedagógico da Escola Plena fundamenta-se em três eixos de formação: Formação Acadêmica de Excelência, Formação para a vida e Formação de competências para o século XXI [ICE, 2016]. Para progresso do aluno nos três eixos de formação, além da permanência na escola por dois períodos ininterruptos (das $7 \mathrm{~h}$ às $16 \mathrm{~h} 30$ ), é ofertada maior carga horária de alguns componentes curriculares da BNCC, além de componentes diversificados tanto para o Ensino Fundamental como para o Ensino Médio da Escola Plena.

Quanto a Grade Curricular do Ensino Fundamental da Escola Plena, ao comparar com uma escola estadual regular que atende os alunos em apenas um período (4 h/a diária), temos uma diferença de $25 \%$ na carga/horária semanal das disciplinas da BNCC, com aumento de $1 \mathrm{~h} / \mathrm{s}$ em cada uma das seguintes disciplinas: Matemática, Língua Portuguesa, Ciências, História e Geografia. Além desse aumento na carga horária dos componentes da BNCC, a Escola Plena também contempla a inclusão de disciplinas diversificadas (Iniciação Científica, Avaliação Semanal, Práticas Esportivas, Estudo Aplicado de Língua Portuguesa, Estudo Aplicado de Matemática, Projeto Educativo Cultural, Disciplina Eletiva e Protagonismo Estudantil), com carga/horária total de $13 \mathrm{~h} / \mathrm{s}$.

Destacamos neste trabalho a disciplina Estudo Aplicado de Matemática, prevista na Base Diversificada do Ensino Fundamental $\left(6^{\circ}\right.$ ao $9^{\circ}$ ano) das Escolas Plenas, com carga horária semanal de $2 \mathrm{~h}$, cujo objetivo é ampliar as possibilidades de desenvolvimento do raciocínio lógico matemático numa perspectiva da alfabetização e do letramento matemático, com atendimento, de "forma inovadora e criativa, às necessidades formativas dos estudantes acerca das habilidades e competências de Matemática". Nesta perspectiva, a metodologia de trabalho deve diferir da dinâmica adotada nas aulas de Matemática da Base Nacional Comum (BNCC), tendo como recomendação a atuação de um professor diferente do regente da Base, o uso de recursos didáticos (jogos, softwares, material dourado, revistas, jornais etc.) e aulas externas ao ambiente escolar (quando possível) [Mato Grosso, 2017, p.18].

O Projeto Político Pedagógico de Educação Integral prevê também que as atividades desenvolvidas na disciplina Estudo Aplicado de Matemática possibilitarão ao aluno compreender que a matemática faz parte de sua vida, a partir de vivências práticas proporcionadas pelo professor, com base nos conhecimentos teóricos trabalhados na disciplina Matemática na BNCC, mas não necessariamente ser uma extensão do que está sendo desenvolvido pelo professor do componente curricular Matemática [Mato Grosso, 2017]. 


\section{A Experiência com a atividade (des)plugada em aula remota}

A prática de computação (des)plugada de que trata o presente artigo foi realizada na disciplina Estudo Aplicado de Matemática de uma Escola Plena com uma turma de $9^{\circ}$ ano do Ensino Fundamental, com vistas a trabalhar conceitos computacionais em paralelo com conceitos da Matemática, com a presença da tecnologia, somente, para contato, interação e mediação com os participantes. Dessa forma, utilizamos em alguns momentos o prefixo "des" entre parênteses para indicar que as atividades realizadas, nesta pesquisa, são impressas ou projetadas na tela para mediação. O material adotado como referência das atividades desenvolvidas com os alunos foi o livro Computer Science Unplugged [Bell; Witten; Fellows, 2011].

As escolas brasileiras, públicas e privadas, tiveram suas atividades presenciais suspensas devido a pandemia Covid-19. Essa situação refletiu no planejamento escolar, bem como na decisão de fazer a prática de CD com uma única professora, pois no modelo remoto temos certos desafios que diferem do ensino presencial tais como, o acesso a ambientes virtuais, comunicação com os participantes, dentre outros. $\mathrm{O}$ planejamento da proposta didática ocorreu durante 4h/a de colaboração da professora regente da turma com uma professora/pesquisadora doutoranda em Educação da UFMT do Grupo de Estudo LêTece ${ }^{1}$. A situação didática transcorreu durante 2h/a da disciplina Estudo Aplicado de Matemática de forma remota, devido à pandemia, com o objetivo de trabalhar conceitos de Exponenciação e sua aplicação/relação na área da Ciência da Computação com conceitos de Números Binários. Após a implementação da proposta, foi realizada uma conversa informal com os alunos para identificar dificuldades e aceite na participação das atividades desplugadas e a intenção em formação futura na área da Ciência da Computação ou Matemática e, uma entrevista semiestruturada com a professora participante com o objetivo de apresentar as percepções da professora regente da disciplina Estudo Aplicado em Matemática quanto ao uso das atividades desplugadas de forma remota, a recepção e participação dos estudantes nas atividades e a relação destas com a disciplina Matemática.

Neste trabalho foram desenvolvidas quatro atividades desplugadas, sendo elas: Números Binários, Contando Acima de 31, Trabalhando com Binários e Enviando Mensagens Secretas. A seleção das atividades teve como base os conceitos e habilidades trabalhados na disciplina Matemática da BNCC, a qual, na escola em questão, é regida por outro professor que não participou da pesquisa.

As quatro atividades selecionadas trabalham com as habilidades: contar, correlacionar e ordenar e, tem a disciplina Matemática como matéria correlata, sendo trabalhado a representação de números em outras bases além da base decimal e representação de números em base dois. Também são trabalhados sequências e padrões sequenciais; descrição de uma regra para um padrão e, padrões e relacionamentos com potências de base dois [Bell; Witten; Fellows, 2011].

A atividade Números Binários consiste em apresentar o conceito de mesmo nome - utilizado pelos computadores e sua relação com o sistema decimal -no cotidiano do aluno. Na atividade Contando Acima de 31 consiste em análises quanto à sequência de números decimais e números binários, bem como a construção de sua

\footnotetext{
1 Laboratório de Estudos sobre Tecnologias da Informação e Comunicação na Educação (https://sites.ufmt.br/letece/).
} 
representação por meio de cartões e a contagem utilizando os dedos. A atividade Trabalhando com Binários consiste em uma sequência de imagens para cada alternativa, que representam os números 0 (zero) e 1 (um). Nesta atividade, o estudante primeiro apresentava o número binário para depois convertê-lo em número decimal. Na atividade Enviando Mensagem Secreta, o estudante precisava decifrar a mensagem enviada por meio de lâmpadas acesas ou apagadas que representam, respectivamente, o número 1 (um) e o número 0 (zero), formando uma sequência binária que tinha como correspondente uma letra do alfabeto e assim, codificar a mensagem.

A situação didática foi desenvolvida de forma remota, com a utilização do Google Meet para videoconferência. A prática foi realizada com uma turma de $9^{\circ}$ ano do Ensino Fundamental, formada por 42 estudante, dos quais 12 participaram da prática. O número reduzido de participantes justifica-se pelo fato de muitos estudantes não possuírem acesso às tecnologias necessárias para a aula remota. Todas as atividades propostas foram realizadas de forma síncrona, em um único dia, com duração de $2 \mathrm{~h} / \mathrm{a}$ da disciplina. As duas professoras atuaram na situação didática, tendo seus papéis divididos da seguinte forma: a professora pesquisadora ficou responsável por trabalhar com os alunos o conceito sobre dados, informações, armazenamento de dados em computadores e números binários, bem como a aplicação/relação que há com o conceito de Exponenciação, utilizando o recurso Google Jamboard ${ }^{2}$ para a exposição de conceitos e exemplificações. Neste primeiro momento, os alunos interagiram com a professora pesquisadora, por meio de perguntas escritas no bate-papo online do Google Meet ou de forma oral utilizando o microfone do Google Meet.

Posterior ao trabalho conceitual, a professora regente, realizou alguns exemplos utilizando o recurso Microsoft Whiteboard $^{3}$ e, em seguida, atribuiu aos alunos a atividade Números Binários e Contando Acima de 31, para ser realizada individualmente, ou seja, o número decimal que cada um teria que converter para número binário, representando-o em potência de base 2 e realizando as análises sugeridas nas atividades.

As atividades Trabalhando com Binários e Enviando Mensagens Secretas foram disponibilizadas aos alunos por meio do compartilhamento de imagem e realizadas pelos alunos individualmente. Todas as atividades propostas foram corrigidas pela professora regente, com supervisão da professora pesquisadora, utilizando o recurso Microsoft Whiteboard, por ser um recurso de fácil manuseio e com a possibilidade de explorar diferentes ferramentas para tornar a aula mais criativa e envolvente.

Para a correção das atividades propostas, a professora regente solicitou aos alunos, de forma individual, sua resolução que poderia ser expressa de forma oral (ativando o microfone), por meio de escrita ou imagem compartilhadas via bate-papo online. Após a exposição do aluno, a professora regente realizava a avaliação da resposta recebida, tendo a participação/interação de outros alunos com seus pareceres durante estes momentos.

A prática realizada na disciplina Estudo Aplicado em Matemática buscou captar e analisar de forma descritiva a situação didática em estudo a partir da perspectiva da pesquisadora por meio da observação-participante e da professora da disciplina por

\footnotetext{
${ }^{2}$ Quadro digital colaborativo da Google.

${ }^{3}$ Tela digital colaborativa do Microsoft 365 .
} 
meio de uma entrevista realizada após a situação didática, considerando pontos relevantes, tais como a leitura e a importância que se dá ao processo de ensinoaprendizagem na Matemática e não apenas aos resultados finais obtidos em avaliação internas e externas.

\section{Resultados e Discussões}

Nesta seção apresentaremos o processo de vivência e as percepções da professora regente da disciplina Estudo Aplicado de Matemática quanto ao uso das atividades desplugadas de forma remota, a recepção e participação dos estudantes nas atividades e a relação destas com a disciplina Matemática.

Durante a entrevista, a professora foi questionada quanto à sua experiência com alguma tecnologia digital de Informação e Comunicação (TDIC) em sua prática pedagógica antes da pandemia. Segundo a professora, ela "não" utilizava TDIC em suas práticas pedagógicas, fazendo-se uso apenas de lousa e canetão. Observa-se que, em razão da pandemia, a professora teve que buscar mais alternativas tecnológicas para desenvolver suas aulas, o que nos faz refletir sobre a formação de professores para o uso, também, de tecnologias de informação e comunicação em suas aulas práticas. Questionada quanto ao conhecimento que considera ter sobre a Área da Ciência da Computação e sua experiência com atividades desplugadas, a professora descreve "Acredito que tenho conhecimento básico na área", = "foi a primeira experiência" com atividades desplugadas, "não conhecia o livro" (Computer Science Unplugged) [Bell; Witten, Fellows, 2011], "mas achei muito interessante".

$\mathrm{Na}$ situação didática foram trabalhadas atividades que envolveram o conceito de números binários. Perguntamos se a professora teve dificuldades com as atividades desenvolvidas com os estudantes e se ela conseguiu perceber se há ou não uma relação entre os conceitos trabalhados em Matemática e a Ciência da Computação. Segundo a professora, não teve "dificuldade nas atividades aplicadas, pois já tinha visto o conteúdo durante a graduação". Para ela, "há sim uma relação entre os conceitos trabalhados em Matemática e na Ciência da Computação".

Após a vivência da atividade desplugada com os alunos, questionamos se a professora incluiria em seu planejamento pedagógico anual atividades de computação desplugada e se haveria possibilidade de interdisciplinaridade em outros momentos na escola. Segunda a professora, "com certeza incluiria". Para ela, "os estudantes precisam conhecer as aplicações da Matemática em outras áreas e saber onde a Matemática está presente na vida deles. Muitos usam a tecnologia, por exemplo, mas não sabem como a Matemática é importante para o seu desenvolvimento. Na escola Plena temos muitos momentos com possibilidade de interdisciplinaridade e, inclusive, somos muito incentivados a fazer isso".

Uma das formações estabelecidas para Escolas Plenas foi a formação STEM ${ }^{4}$, que iniciou no ano de 2017 às áreas de Ciências da Natureza e da Matemática, sendo mediada pela entidade privada (sem fins econômicos) STEM Brasil [Lima; Dahmer; Sassi, 2020, p. 11] e, além da formação, o Programa de Ensino Médio em Tempo Integral (EMTI) - Escola Plena prevê em sua estrutura pedagógica um movimento

\footnotetext{
${ }^{4}$ Acrônimo em inglês para designar as palavras Science, Technology, Engineering e Mathematics (Ciências, Tecnologia, Engenharia e Matemática).
} 
interdisciplinar, com planejamento por área e entre áreas, bem como procedimentos teórico-metodológicos que favoreçam a experimentação de atividades dinâmicas, contextualizadas e significativas nos diversos campos das ciências.

A recomendação quanto ao desenvolvimento de atividades desplugadas é um fator positivo para a professora. Ela destaca a necessidade de uma formação continuada para os colegas de profissão, como o desenvolvimento de "uma oficina ou minicurso sobre o tema seria de grande valia, pois poderíamos apresentar essas atividades para todos os professores e incentivá-los a aplicá-las". Notamos na fala da professora a possibilidade e necessidade de formação específica para os professores trabalharem com atividades que envolvam conceitos da área da Ciência da Computação, para assim atualizarem e melhorarem suas práticas pedagógicas. Atualmente, algumas formações relacionadas a Pensamento Computacional, robótica, dentre outros, têm sido disponibilizadas pelo Ministério da Educação (MEC) em formações online por meio da plataforma AVA - $\mathrm{MEC}^{5}$, de forma gratuita. Porém, tais formações, muitas vezes não são apresentadas aos professores da rede.

Durante a prática com atividades desplugadas, observamos a participação/interação dos alunos com as professoras. Quanto à receptividade dos alunos diante das atividades desplugadas propostas, a professora regente avalia que "Por conta da aula online, é dificil saber exatamente como foi a receptividade dos alunos, mas pode-se dizer que aqueles que se manifestaram mostraram bastante interesse na atividade proposta". A manifestação dos estudantes, relatados pela professora, ocorreu via mensagem no bate-papo online ou por meio do microfone (áudio) do Google Meet. Porém, o Microsoft Whiteboard, utilizado para a resolução das atividades pela professora regente, possui a ferramenta de convidar e permite a interação de outros na lousa digital, o que não foi utilizado durante a prática.

Com base no que foi observado pela professora, perguntamos qual a percepção dela quanto à participação, motivação ou dispersão dos estudantes durante a realização da prática. Segundo a professora, "mesmo com a aula online, os alunos se mostraram mais participativos durante a aula com a atividade desplugada do que nas aulas "convencionais". Alguns se mostraram mais motivados que outros, talvez por apresentarem maior interesse na Área da Ciência da Computação. Outros, infelizmente, se dispersaram e acabaram saindo da reunião". Dos 12 estudantes participantes da prática, houve 2 (dois) alunos que saíram da reunião, sem sabermos o real motivo, o que nos leva a aventar a possibilidade de dispersão ou falta de interesse. Porém, não podemos esquecer os contratempos que podem ocorrer, tais como a falta de conexão para participar da aula remota. Quanto à participação, temos destaque para uma aluna que confirmou ter vontade de fazer uma graduação em Matemática, o que a fez querer participar e aprender mais, e um aluno que confirmou a vontade de graduar na Área da Ciência da Computação por ter como exemplo em sua vida seu tio com tal formação acadêmica.

Quanto às dificuldades dos estudantes no desenvolvimento das atividades, perguntamos se foi possível perceber obstáculos dessa ordem durante a realização da prática. Para a professora, "a maior dificuldade, nesse momento é não conseguir

\footnotetext{
5 Ambiente Virtual colaborativo de Aprendizagem que permite a concepção, administração e desenvolvimento de diversos tipos de ações formativas do Ministério da Educação.
} 
identificar quais alunos estão realmente prestando atenção, quais estão desenvolvendo as atividades e quais não estão nem sequer assistindo a aula, pois aqueles que sentem dificuldade ou simplesmente não gostam do conteúdo saem da reunião sem dar explicações".

Para a professora, a dificuldade na aplicação das atividades desplugadas via remota é a mesma nas outras atividades desenvolvidas com os estudantes, pois "não conseguimos ter o contato pessoal com o aluno, não conseguimos saber se eles estão mesmo entendendo o que está sendo trabalhado, se estão interessados na aula, se estão prestando atenção e se estão conseguindo acompanhar. As dificuldades são semelhantes àquelas que encontramos em todas as aulas, a falta de contato "olho no olho"'." Observamos no relato da professora que as dificuldades vão além do avaliar os estudantes em aula remota, ela reforça a dificuldade de estabelecer uma interação durante as aulas remotas, seja com perguntas e/ou respostas quanto aos conceitos trabalhados, o que não possibilita um olhar mais próximo do aluno. $\mathrm{O}$ ato normativo quanto as aulas nas escolas estaduais de Mato Grosso, apresenta a possibilidade do aluno na escolha do desenvolvimento de seus estudos, tendo a não obrigatoriedade na participação das aulas remotas, ficando apenas a entrega das atividades avaliativas por meio impresso ou via Ambiente Virtual de Aprendizagem (AVA) Google Classroom, o que limita ao professor o contato próximo ao aluno que um diálogo possibilita.

Diante dessa situação didática, vivenciada pela professora/pesquisadora, sistematizamos e apresentamos no Quadro 1 algumas percepções quanto ao material utilizado, participação dos alunos e a prática docente, com respectivas recomendações para o trabalho com atividades desplugadas durante aulas remotas.

\section{Quadro 1. Percepções e recomendações para aplicação de atividades desplugadas} em aulas remotas

\begin{tabular}{|c|c|c|}
\hline \multicolumn{2}{|r|}{ Percepções } & Recomendações \\
\hline $\begin{array}{l}\text { Uso do } \\
\text { material de } \\
\text { CD }\end{array}$ & $\begin{array}{l}\text { - Fácil entendimento mesmo } \\
\text { sendo em aula remota } \\
\text { - Possibilidade de relação } \\
\text { com a matemática }\end{array}$ & $\begin{array}{l}\text { - Adaptar as atividades conforme contexto, utilizando } \\
\text { de tecnologias que possibilitem a mediação e interação } \\
\text { dos alunos } \\
\text { - Realizar mais vivências } \\
\text { - Relacionar os conceitos trabalhados com situações do } \\
\text { dia a dia e com os conceitos matemáticos }\end{array}$ \\
\hline $\begin{array}{c}\text { Participação } \\
\text { dos alunos }\end{array}$ & $\begin{array}{l}\text { - Pouca interação entre os } \\
\text { alunos e com o docente } \\
\text { - Facilidade na resolução das } \\
\text { atividades }\end{array}$ & $\begin{array}{l}\text { - Usar as ferramentas presentes nos recursos } \\
\text { tecnológicos/práticas pedagógicas para melhorar a } \\
\text { interação dos alunos } \\
\text { - Aplicar atividades desplugadas relacionadas aos } \\
\text { conceitos trabalhados como parte da disciplina } \\
\text { Matemática, já constando no planejamento do } \\
\text { professor }\end{array}$ \\
\hline $\begin{array}{l}\text { Prática } \\
\text { docente }\end{array}$ & $\begin{array}{l}\text { - Primeira experiência com } \\
\text { uso de TIC para prática } \\
\text { docente } \\
\text { - Primeira experiência com } \\
\text { CD } \\
\text { - Facilidade no entendimento } \\
\text { dos conceitos e na relação } \\
\text { com a disciplina }\end{array}$ & $\begin{array}{l}\text { - Participar em formações específicas sobre } \\
\text { Computação Desplugada e uso de tecnologias na } \\
\text { educação } \\
\text { - Realizar mais práticas, com a participação do aluno } \\
\text { na avaliação da proposta em busca de melhoria } \\
\text { - Analisar o contexto em que ocorrerá a prática, } \\
\text { levando em consideração o estudante e a estrutura } \\
\text { física/tecnológica/ pedagógica necessária }\end{array}$ \\
\hline
\end{tabular}

Fonte: Elaborado pelos autores 


\section{Considerações Finais}

Este artigo tem como foco no uso da Computação (Des)plugada na Educação Básica, apresentando um relato de experiência de ensino do conceito de Números Binários para alunos do $9^{\circ}$ ano do Ensino Fundamental de uma Escola Plena, realizado na aula da disciplina Estudo Aplicado de Matemática, pela professora pesquisadora da área da educação, com foco na Computação Desplugada e a professora regente da turma, ambas Licenciadas em Matemática, tendo como foco a percepção da professora regente da disciplina quanto ao uso de atividades desplugadas em suas aulas remotas e a aproximação do conceito de Números Binários com a Matemática.

Foram desenvolvidas quatro atividades desplugadas, sendo elas: Números Binários; Contando Acima de 31; Trabalhando com Binários; Enviando Mensagens Secreta; com foco nas habilidades contar, correlacionar e ordenar. Não há como desassociar a pandemia Covid-19 vivenciada e os reflexos causados na educação. $O$ estudo desenvolvido apresentou resultados importantes quanto às dificuldades encontradas pelos professores para desempenhar seu trabalho durante a pandemia que $o$ mundo está vivenciando desde 2020. Além do número reduzido de alunos que participam das aulas remotas devido à falta de acesso às tecnologias, a falta de interação dos alunos participantes dificulta o planejamento e o trabalho pedagógico.

Neste experimento, segundo a professora, fica difícil identificar se os alunos estão participando, pois os mesmos pouco interagem com perguntas e respostas e não disponibilizam a captação de sua imagem pela câmera do dispositivo. Os estudantes que interagiram durante a realização das atividades desplugadas mostraram interesse e pouca dificuldade na execução, utilizando o chat do Google Meet para expor sua resolução ou dúvidas. Também foi possível perceber a possibilidade do trabalho interdisciplinar entre a Ciência da Computação e a Matemática, com foco nas habilidades e conceitos computacionais por meio de atividades que trabalharam conceitos matemáticos como potência, multiplicação, adição, sequência e conversão.

Com base na prática vivenciada, foi possível apresentar percepções docente, sendo categorizado em três eixos: o uso do material de CD que trabalham com conceitos e habilidades da Ciência da Computação e da Matemática; participação dos estudantes na prática com atividades (des)plugadas; a prática docente com atividades (des)plugadas em aulas remotas, com recomendações possíveis a serem seguidas em busca de melhoria nos resultados pedagógicos. Recomendações estas, que podem ser revisadas, melhoradas e adaptadas para cada contexto. Entende-se que a aplicação do estudo exploratório em mais disciplinas poderia ser ideal, todavia as atividades estão associadas aos conteúdos e ano escolar. E cada experiência em sala de aula é única. Ressalta-se que são limitados os registros de práticas de CD no ensino remoto, o que não nos permitiu estudos comparativos neste campo.

As percepções neste estudo, estão permeadas com questões afetas ao momento pandêmico que vivenciamos, de ensino remoto e seus desafios. Como trabalhos futuros, esperamos aumentar o tempo de experiência por meio de implementação de projeto, o número de professores e analisar o relato dos alunos, uma vez que se faz necessário o assentimento dos pais, bem como realizar uma análise qualitativa das atividades propostas tendo como foco as habilidades matemáticas envolvidas e a realização de interdisciplinaridade. Também planeja-se realizar experiências buscando contemplar outros conceitos computacionais e relacioná-los com a disciplina de Matemática. 


\section{Agradecimentos}

Essa pesquisa contou com o apoio do Conselho Nacional de Desenvolvimento Científico e Tecnológico - CNPq e da Secretaria de Estado de Educação de Mato Grosso-SEDUC.

\section{Referências}

Bell, T.; Witten, I. H.; Fellows, M. “Computer Science Unplugged”. 2011. Disponível em: $\quad<$ https://classic.csunplugged.org/wpcontent/uploads/2014/12/CSUnpluggedTeachers-portuguese-brazil-feb-2011.pdf $>$. Acesso em: 04/11/2020.

Brasil. Base Nacional Comum Curricular (BNCC). (2021). Disponível em: $<$ http://basenacionalcomum.mec.gov.br/images/BNCC_EI_EF_110518_versaofinal_ site.pdf $>$. Acesso em 11/03/2021.

Figueiredo, L. et al. "Código X em Casa: um relato de experiência sobre o ensino remoto de computação desplugada para meninas em situação de vulnerabilidade socioeconômica, em tempos de distanciamento social". (2020). In: Workshop de Informática na Escola (WIE), 26. Natal. Novembro, 2020. p. 279-288.

ICE, Instituto de Corresponsabilidade pela Educação. "Modelo Pedagógico: Princípios Educativos". 2ºd. Recife-PE, 2016.

Lima, Waleska G; Dahmer, Cláudia Inês; Sassi, Sabrina B. "As práticas STEM na implementação do Projeto de Educação em Tempo Integral de Mato Grosso". In: Seminário de Educação - Semiedu. Cuiabá. 2020.

Mato Grosso. SEDUC. Portaria No 035/2016/GS/SEDUC/MT. Cuiabá, Mato Grosso, 2016.

Mato Grosso, SEDUC/MT. "Projeto Pedagógico de Educação Integral”. Cuiabá, Mato Grosso, 2017.

Mato Grosso, DECRETO N ${ }^{0}$ 510, DE 03 DE JUNHO DE 2020. Disponível em: $<$ http://www.transparencia.mt.gov.br/documents/363605/14442674/DECRETO+N\% $\mathrm{C} 2 \% \mathrm{BA}+510 \% 2 \mathrm{C}+\mathrm{DE}+03+\mathrm{DE}+\mathrm{JUNHO}+\mathrm{DE}+2020 . \mathrm{pdf} / 99397 \mathrm{c} 4 \mathrm{e}-9368-0146-\mathrm{cd} 32-$ dc997ef49b48>. Acesso em: 31/03/2021.

Sassi, S. B.; Maciel, C.; Pereira, V.C. (2021). Revisão sistemática de estudos sobre Computação Desplugada na Educação Básica e Superior de 2014 a 2020: Tendências no campo. Revista Contexto \& Educação, 36(114), 10-30.

WHO (2020). World Health Organization. Disponível em: <https://www.who. int/emergencies/diseases/novel-coronavirus-2019/ situation-reports>. Acesso: 04/03/2021. 